\title{
Pulmonary Tumor Thrombotic Microangiopathy: A New Paraneoplastic Syndrome?
}

\author{
Corey A. Carter ${ }^{a}$ Jan J. Scicinski ${ }^{b}$ Harry E. Lybeck ${ }^{c}$ Bryan T. Oronsky ${ }^{b}$ \\ ${ }^{a}$ Murtha Cancer Center, Walter Reed National Military Medical Center, Bethesda, Md., and \\ ${ }^{b}$ EpicentRx Inc., Mountain View, Calif., USA; ${ }^{c}$ Department of Physiology, \\ Helsinki University, Helsinki, Finland
}

\section{Key Words}

Pulmonary tumor thrombotic microangiopathy - Paraneoplastic syndrome - Diagnosis .

Adenocarcinoma

\begin{abstract}
This report, based on data from a clinical case, proposes that pulmonary tumor thrombotic microangiopathy, an underdiagnosed cause of pulmonary hypertension and death in patients with adenocarcinoma, is a paraneoplastic syndrome (PNS). Clinicians in general must be alert to the presence or development of PNS that may precede, coincide with, follow, or herald the recurrence or the primary diagnosis of malignancy since early recognition facilitates prompt diagnosis and treatment.

(C) 2016 The Author(s)

Published by S. Karger AG, Basel
\end{abstract}

\section{Introduction}

Clinicians in general must be alert to the presence or development of paraneoplastic syndromes (PNS) that may precede, coincide with, follow, or herald the recurrence or the primary diagnosis of malignancy since early recognition facilitates prompt diagnosis and treatment. PNS is defined as a 'pathology caused by tumor cells, which systematically produce a large amount of hormones, growth factors, cytokines and a variety of specific symptoms' [1]. Examples of PNS, associated with metabolic, mucocutaneous, hormonal and neurological symptoms [2], include dermatomyositis-polymyositis, Cushing syndrome, carcinoid syndrome, myasthenia gravis and syndrome of inappropriate antidiuretic hormone [3]. To this list of distinct PNS we would add a rare, fatal and likely underdiagnosed cause of pulmo-

\section{KARGER}


Carter et al.: Pulmonary Tumor Thrombotic Microangiopathy: A New Paraneoplastic Syndrome?

nary hypertension known as pulmonary tumor thrombotic microangiopathy (PTTM) that is seen in patients with adenocarcinomas [4].

\section{Case and Discussion}

Herein, we report a case of PTTM in a 47-year-old female with triple-negative breast cancer. Initially, this patient who developed fever and tachycardia during treatment on a clinical trial was hospitalized to rule out/treat infection. The next day she developed dyspnea, hypoxemia, and ground glass opacities on a CT scan. The lack of a response to broadspectrum antibiotics suggested an alternate diagnosis to pneumonia. On transthoracic echocardiography, which was ordered over 1 week later, the cause of her dyspnea was revealed to be acute cor pulmonale. Together with an elevated D-dimer and a prolonged prothrombin time in the setting of a V/Q scan with a low probability for pulmonary embolism a diagnosis of PTTM, a rare arteriopathy associated with coagulation cascade activation and vascular remodeling [5] was made.

Based on the pathogenesis of PTTM, which is related to the secretion of vascular remodeling factors [6] including vascular endothelial growth factor, fibroblast growth factor, and platelet-derived growth factor the plan was to treat the patient with sunitinib [7], a multitargeted tyrosine kinase inhibitor that blocks vascular endothelial growth factor and plateletderived growth factor receptors. While she unfortunately died before treatment with sunitinib could begin, it is reasonable to assume that earlier diagnosis and treatment would have resulted in a better outcome.

Due to this paraneoplastic-like secretion of vascular and vascular smooth muscle mitogens, we suggest that PTTM meets the definition of a PNS. In the absence of a biopsy, echocardiographic and coagulation studies [8] are the diagnostic tests of choice.

As PTTM is a heretofore potentially unrecognized PNS, we suggest that the acute or subacute development of cor pulmonale should prompt an evaluation for new, recurrent, or worsening malignancy.

\section{Statement of Ethics}

The clinical research behind this report complies with the guidelines for human studies. Any subjects have given their informed consent and the study protocol has been approved by the relevant institute's institutional review board (IRB).

\section{Disclosure Statement}

The authors declare that they have no conflicts of interest to disclose.

\section{References}

-1 Cui T, Hurtig M, Elgue G, Li SC, Veronesi G, Essaghir A, Demoulin JB, Pelosi G, Alimohammadi M, Öberg K, Giandomenico V: Paraneoplastic antigen Ma2 autoantibodies as specific blood biomarkers for detection of early recurrence of small intestine neuroendocrine tumors. PLoS One 2010;5:e16010.

2 Kanaji N, Watanabe N, Kita N, Bandoh S, Tadokoro A, Ishii T, Dobashi H, Matsunaga T: Paraneoplastic syndromes associated with lung cancer. World J Clin Oncol 2014;5:197-223. 
3 Pelosof LC, Gerber DE: Paraneoplastic syndromes: an approach to diagnosis and treatment. Mayo Clin Proc 2010;85:838-854.

4 Marumo S, Sakaguchi M, Teranishi T, Higami Y, Koshimo Y, Katob M: Pulmonary tumor thrombotic microangiopathy induced by ureteral carcinoma: a necropsy case report. Case Rep Oncol 2014;7:605-610.

5 Kumar N, Price LC, Montero MA, Dimopoulos K, Wells AU, Wort SJ: Pulmonary tumour thrombotic microangiopathy: unclassifiable pulmonary hypertension? Eur Respir J 2015;46:1214-1217.

6 Chinen K, Kazumoto T, Ohkura Y, Matsubara O, Tsuchiya E: Pulmonary tumor thrombotic microangiopathy caused by a gastric carcinoma expressing vascular endothelial growth factor and tissue factor. Pathol Int 2005;55:27-31.

-7 Roskoski R Jr: Sunitinib: a VEGF and PDGF receptor protein kinase and angiogenesis inhibitor. Biochem Biophys Res Commun 2007;356:323-328.

-8 Gainza E, Fernández S, Martínez D, Castro P, Bosch X, Ramírez J, Pereira A, Cibeira MT, Esteve J, Nicolás JM: Pulmonary tumor thrombotic microangiopathy: report of 3 cases and review of the literature. Medicine (Baltimore) 2014;93:359-363. 